\section{French city heading towards Technopolis} Paris

THE first in-depth review of an experiment in technological innovation introduced in France in 1984 has recently been published* by a group of economists at the Centre National de la Recherche Scientifique (CNRS). The project aims to stimulate regional nuclei of high technology competence (technopôles) by creating a network of consultants from local universities and state research centres who collaborate with industry. The experience at one of these technopôles, Sophia-Antipolis in the South of France, suggests that a new phenomenon is being born.

Instead of the traditional science park, which can be no more than a juxtaposition of research and industrial competence, Sophia-Antipolis could, the report says, become a 'technopolis' - a flexible infrastructure which promotes technology innovation as well as technology transfer. Such transfer is necessary, but is not sufficient for manufacturers to respond to demands for creation of new technology.

Companies at Sophia-Antipolis, which include the information technology multinational Digital Equipment and the electronics company Thomson-Sintra, are moving away from rigid management and production structures which only exploit existing technology developments. By using modular, multi-purpose production lines and creating project-oriented 'task forces', including consultants from universities, companies can create new technologies which are tailored to the client's demands. In this way, ThomsonSintra was able to use expertise gained in the development of sonar devices for submarines to create equipment to locate faults in the cooling system of the prototype Superphénix nuclear energy reactor, which has been out of service for over a year.

The CNRS report finds few faults with developments at Sophia-Antipolis. Rather, it is concerned that ad hoc principles of collaboration be reinforced in order to assure a "perennial success" in responding to demands for new technology. The role of industry in researcher training is seen as paramount - a role which successive governments have criticized as insufficient. But leading engineering academies also need to review their role. At present, few offer facilities for research to doctoral level and graduates tend to shy away from careers in state research organizations, such as CNRS. Without better-trained research engineers, France could fall behind in the all-important race for new technologies, despite successes like SophiaAntipolis.

Peter Coles

${ }^{*}$ Technopote et Developpement, available from J.-L. Ravix CNRS. Avenue Albert Einstein, (6560 Valbonne, France.

\title{
New initiative in Japan to develop neural networks
}

Tokyo

JAPAN is getting ready to make a big splash in the world of neural network computers. Within the next few months the Ministry of International Trade and Industry (MITI) will announce the formation of a study group to lay plans for a new national neurocomputer project. Although details are not known, it is expected that the project will match the fifth generation computer project in scale.

Japan has solid foundations in neurocomputing set in the 1960 s when there was a feverish burst of research activity in laboratories around the world. When the field went out of fashion, a few basic researchers continued working in Japanese laboratories. Now that the topic is generating excitement worldwide, their research and new projects could provide the core for a national effort.

Noboyuki Ohtsu, section chief of the mathematical engineering section of the computer science division at MITI's Electrotechnical Laboratory (ETL) and a key adviser to MITI, expects that the project will have four main topics: theory and fundamental research on neural network models; architecture and parallel processing; devices, including optical devices; and application technology. But he stresses that the topics are still "not so clear".

Like Ohtsu, Professor Shunichi Amari of Tokyo University hopes that the project will concentrate on theoretical work in the initial stages. Amari is another key MITI adviser and one of those who continued research during the $1970 \mathrm{~s}$. He says much more needs to be done before a commercial neurocomputer can be built, and at this stage it is impossible to predict what kind of machine it will be.

The study group, which will be established next spring with a budget of $¥ 20$ million will look at optical, fuzzy and parallel computing as well as neurocomputing. But the chances are that it will come up with a national project that will attempt to replace the fifth-generation computer project while avoiding its shortcomings.

Despite all the publicity — and $¥ 30,000$ million in government support since 1982 - the fifth generation computer project is not seen as a success. Industry will be reluctant to contribute its best researchers to a second project based around a single institute. And ETL researchers are wary of getting dragged into management of another large-scale national project. Thus it is expected to take MITI one or two years to reach a final consensus on how the neurocomputing project should be structured.
Gen Matsumoto of MITI's Electrotechnical Laboratory in Tsukuba, who is studying the squid giant axon, heads the 'bioarchitecture' group within a MITIsponsored 'bioelectronics devices' project, now in its second year, aimed at developing new algorithms and simulations for neurocomputing through the study of living organisms. Industrial partners include Fujitsu and NEC.

Before the national project takes off, substantial government funds will be

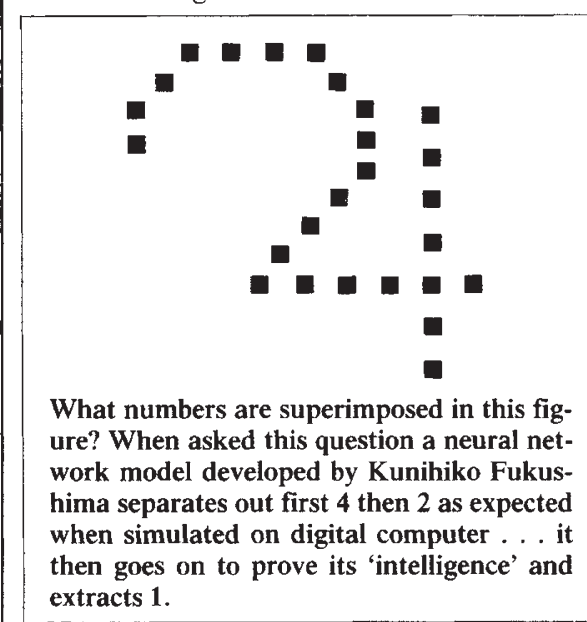

poured into neurocomputing at a new institute set up by the Ministry of Post and Telecommunications. The Advanced Telecommunications Research Institute (ATR) in Osaka was established in 1986 with funds from private industry and the Japan Key Technology Centre. ATR has an annual research and development budget of about $¥ 9,000$ million ( $\$ 70$ million) and 200 researchers, about ten per cent of whom are working on neural network projects.

For example, Mitsuo Kawato of ATR's Auditory and Visual Perception Laboratory is collaborating with Bridgestone in the development of neural networks to control robot movement.

And Sei Miyake of the same laboratory is developing the 'neocognitron', a neural network model developed by Kunihiko Fukushima of NHK Science and Technical Research Laboratory which can distinguish and read handwritten numbers (see figure). Miyake has adapted the "neocognitron' to run on a $\$ 2$ million NCUBE parallel-processing computer and it can separate out and 'recognize' 4-digit numbers in $0 \cdot 8$ seconds.

Although MITI and the Ministry of Post and Telecommunications are arch rivals, Kawato says there are no barriers between researchers in the field of neurocomputing in Japan. Nearly all the researchers at ATR are seconded from private companies. 